\title{
DESARROLLO RURAL A TRAVÉS DEL TURISMO COMUNITARIO. ANÁLISIS DEL VALLE Y CAÑÓN DE COLCA.
}

\author{
Jaime Pastor, V. \\ Universidad de Valencia \\ vjaime@uv.es \\ Casas Jurado, C. \\ Universidad de Valencia \\ ccasas@ugr.es
Amparo Soler Domingo
Universidad de Granada
amparosoler@ugr.es

\section{RESUMEN}

El turismo comunitario es una nueva modalidad turística que se está desarrollando en la región andina de Latinoamérica como alternativa al turismo tradicional. Esta tipología turística permite la conservación del medio ambiente y la participación de la comunidad local en la gestión turística del territorio.

En el presente documento se va a analizar la importancia del turismo comunitario en Valle y Cañón de Colca, situado en la región de Arequipa. Para justificar dicha propuesta en primer lugar se va a definir conceptualmente el Turismo Comunitario, incluyendo una revisión de las directrices de política turística. Después se va a realizar un análisis de las características socio-económicas de la región que justifican y refuerzan el empleo de dicho modelo de gestión; seguidamente se analiza el destino turístico tanto desde una perspectiva territorial como desde el tradicional análisis de oferta y demanda, y por último, se expondrá los resultados obtenidos del primer proyecto de turismo comunitario que se ha puesto en marcha en esta zona.

Palabras clave: Turismo comunitario, turismo rural, turismo sostenible, desarrollo local, Arequipa, Valle del Colca. 


\title{
THE RURAL DEVELOPMENT OF COMMUNITY-BASED TOURISM IN COLCA VALLEY AND COLCA CANYON.
}

\author{
Vicente Jaime Pastor \\ Universidad de Valencia \\ vjaime@uv.es \\ Cristina Casas Jurado \\ Universidad de Granada \\ ccasas@ugr.es
Universidad de Granada
amparosoler@ugr.es \\ Amparo Soler Domingo
}

\begin{abstract}
The Community-based Tourism is a new tourist modality that is developing in the Andean region of Latin America as alternative to the traditional tourism. This tourist typology permits the conservation of the environment and the participation of the local community in the tourist management of the territory.

The present document analyzes the importance of the Community-based Tourism in Colca Valley and Colca canyon, both located in the region of Arequipa. To justify the present proposal, the concept of Community-based place, include a review of tourism politics guidelines. Secondly, an analysis of the social-economic features of the region that justify and reinforce its use is carried out; next, the tourism destination is examined from territorial perspective and from a traditional analysis of supply and demand. Finally, the results obtained in the first Community-based tourism project developed in the area, are analyzed.
\end{abstract}

Key words: Community-based Tourism, Rural Tourism, Sustainable Tourism, Local development, Arequipa, Valle del Colca. 


\section{1. - INTRODUCCIÓN}

El presente documento propone el modelo de gestión de turismo comunitario como alternativa adecuada al desarrollo del Valle y Cañón de Colca, situado en la región de Arequipa. Esta modalidad de desarrollo turístico de la región es la forma más viable y sostenible a largo plazo de mejorar la conservación del medioambiente y conseguir una mayor implicación de la población local en la gestión turística de la región. Para justificar dicha propuesta en primer lugar se va a definir conceptualmente el Turismo Comunitario, incluyendo una revisión de las directrices de política turística. Después se va a realizar un análisis de las características socio-económicas de la región que justifican y refuerzan el empleo de dicho modelo de gestión; seguidamente se analiza el destino turístico tanto desde una perspectiva territorial como desde el tradicional análisis de oferta y demanda y, por último, se analizará la aplicación de este modelo de gestión turística en la zona objeto de estudio.

En las últimas décadas el sector turístico se ha visto inmerso en un intenso proceso de potenciación de la participación de las comunidades locales en los países en vías de desarrollo que se materializan en iniciativas de Turismo Comunitario. En este trabajo se pone de manifiesto el importante impacto del turismo en la economía regional de la región constatando que tiene una serie de características idóneas para la implementación de iniciativas de Turismo Comunitario; bajo nivel de desarrollo agrario e industrial, elevados índices de pobreza y desempleo.

Lo que se pretende con esta investigación es analizar la actividad turística de la región desde la perspectiva del Turismo Comunitario para incidir en la necesidad de potenciar la participación de las comunidades locales en el futuro modelo de desarrollo y gestión de la actividad turística de la zona.

\section{2.- TURISMO COMUNITARIO: ASPECTOS CONCEPTUALES}

El concepto turismo comunitario aparece por primera vez en la obra de Murphy (1985) donde se analiza aspectos relacionados con el turismo y las áreas rurales de los países menos adelantados y posteriormente en otros trabajos de investigación del mismo autor (Murphy y Murphy, 2004) y en los de Richards y Hall (2000), en el que plantea el turismo como herramienta para reducir la pobreza. 
Este tipo de turismo es adecuado en los países latinoamericanos, ya que es una herramienta fundamental para reducir el nivel de pobreza de las áreas más deprimidas y contribuir a su crecimiento económico. Existen varios proyectos de turismo comunitario en América Latina. Concretamente en Ecuador (Ruiz et al, 2008), Brasil (Guerreiro, 2007), México (Juárez y Ramírez, 2007), Nicaragua (Lopéz-Guzmán, T. y Sánchez Cañizares, S., 2009a) y El Salvador (LópezGuzmán, T. y Sánchez Cañizares, S., 2009). En Chile hay varias iniciativas de turismo comunitario. Concretamente a través de la Fundación sendero de Chile $^{1}$ y para otras iniciativas ver al autor Morales Morgado (2006).

El pues una realidad que el turismo comunitario está apareciendo con fuerza en la región andina y que esencialmente está basado en la comunidad local y en la gestión del territorio. Es una modalidad turística en la que la comunidad local participa de forma activa en este tipo de actividad y permite generar riqueza en las áreas rurales de los países de Latinoamérica, a través de la participación de la comunidad local en la gestión turística, de forma que los beneficios obtenidos repercutan en la propia comunidad. Además, es capaz de promover el desarrollo integral de las comunidades tratando de reducir la pobreza a través de la generación de empleo y la obtención de ingresos complementarios, evitando los movimientos migratorios (Inostroza, G. 2009). Esta modalidad turística ofrece la oportunidad de crear pequeños negocios intensivos en mano de obra y da empleo a un porcentaje de mujeres relativamente superior al de otros sectores (World Tourism Organization, 2003), sin olvidar que la comunidad local es la parte esencial del producto turístico (López- Guzmán, T. y Sánchez Cañizares, S. M., 2009).

La gestión territorio cobra mucha importancia ya que es necesario que el turismo sea respetuoso con el medio ambiente y responsable con el entorno social (Kay, C. 2007). Un turismo inadecuado puede degradar el hábitat y agotar los recursos naturales, mientras que el turismo sostenible y responsable puede ayudar a la conservación del medio rural y la cultura local. Además, los recursos pueden ser manejados mejor de forma colectiva que individual, ya que a través de la gestión local se puede hacer un mayor control social sobre el uso (Inostroza, G. 2009), por ello es necesario estimular el turismo responsable que no solo mejore la calidad de vida de las áreas rurales sino los recursos naturales y culturales de los lugares de destino (WWF Internacional, 2001). También ha de ser soportable ecológicamente a largo plazo, viable económicamente y equitativo desde una perspectiva ética y social para las comunidades locales. Una buena gestión turística debe

\footnotetext{
${ }^{1}$ http://www.senderodechile.cl/portal/turismo-comunitario/
} 
conservar los espacios naturales ya que la naturaleza y la cultura son el soporte de la actividad turística.

El objetivo de esta modalidad turística es preservar la identidad étnica, la valoración y la transmisión del patrimonio cultural en todas sus formas, ya que las culturas autóctonas son portadoras de valores, historia e identidad (Maldonado, 2005).

El Turismo Comunitario aporta importantes beneficios en las áreas rurales de estos países, ya que, en primer lugar, tiene un impacto directo en las familias de la población local, en el desarrollo socioeconómico de la región y en el estilo de vida (Manyara y Jones, 2007); en segundo lugar, estimula un turismo responsable que mejore además de la calidad de vida de las áreas rurales los recursos naturales y culturales de los lugares de destino (WWF Internacional, 2001) y, por último, es una forma de erradicar la pobreza. En este sentido, la Organización Mundial del Turismo (WTO, 2002) plantea el turismo comunitario como una forma de erradicar la pobreza con iniciativas como el programa de la World Tourism Organization denominado Sustentable Tourism for the Elimination of Poverty; No olvidemos que el turismo es el principal exportador de servicios para países en vías de desarrollo y tiene un gran potencial para brindarles ventajas competitivas. Además, es la fuente principal de ingresos y de entrada de divisas y en algunos países representan el $40 \%$ de su PIB (Bolwel D. y Weinz, W., 2009).

La implantación de turismo comunitario en las áreas rurales de Perú puede provocar (MINCETUR, 2008b), en lo económico, la dinamización la economía local en la medida en que es una actividad complementaria y no sustitutiva de la agricultura; en lo ambiental, la promoción de un turismo rural sostenible que conserve el medio ambiente y optimice la gestión de recursos naturales; en lo social, la aparición del concepto de asociacionismo, ya que importantes recursos naturales, como el agua y las extensiones de terreno, son de uso comunitario; en lo cultural y educativo, la contribución a la recuperación de la cultura, su gastronomía, folclore, costumbres y permite que los turistas conozcan la pluriculturalidad, el multilingüismo y la biodiversidad del país; y, por último, la oportunidad de la atracción de turistas que practican una conducta responsable con el medio ambiente.

Un elemento esencial para el éxito del turismo comunitario es el papel que debe adoptar la comunidad local en la planificación y gestión de la actividad turística, ya que sirve para adaptarse a los cambios, abre su mentalidad y son parte esencial del producto turístico (López- Guzmán, T. y 
Sánchez Cañizares, S. M. ,2009). Pero el impacto que tiene este tipo de turismo depende del grado de implicación de la población indígena y del nivel de acuerdo de las Administraciones Públicas y la existencia de infraestructura, aspectos que serán analizados más adelante.

La importancia del turismo comunitario queda recogido, a nivel nacional, en el Plan Estratégico Nacional de Turismo de Perú- PENTUR (2008) que tiene como objetivo central "alcanzar un turismo sostenible como herramienta de desarrollo económico-social de Perú” y en los Lineamientos para el Turismo Comunitario en el Perú (MINCETUR, 2008b). A nivel regional, en el Plan Estratégico Institucional de Arequipa (MINCETUR, 2008a) y en el Plan estratégico Regional de Turismo en Arequipa, 2011-2015 (MINCETUR, 2010). Además, hay un proyecto "Desarrollo y Fortalecimiento del Turismo Rural Comunitario en Perú (TURURAL-PERÚ)” auspiciado por el Ministerio de Comercio Exterior y Turismo de Perú, el Gobierno Regional de Arequipa y la Agencia española de Cooperación Internacional al Desarrollo dirigido a mejorar el desarrollo económico y social del valle de Colca, concretamente el municipio de Sibayo, a través del turismo rural comunitario, el cual analizaremos más adelante. Los resultados de este proyecto serán analizados en epígrafes posteriores.

\section{3.- CARACTERÍSTICAS SOCIO-ECONÓMICAS DEL VALLE Y CAÑÓN DE COLCA}

El Cañón del Colca es una formación geológica producida por una falla en la corteza terrestre erosionada por las aguas del río del mismo nombre. La zona se halla rodeada por volcanes y se localiza en la provincia de Caylloma en la región de Arequipa, limita con Cusco y Puno. Su espacio turístico rebasa las fronteras geopolíticas de los distritos. Ocupa 11.990 Kilómetros cuadrados de extensión y cuenta con más de 19.000 habitantes. 


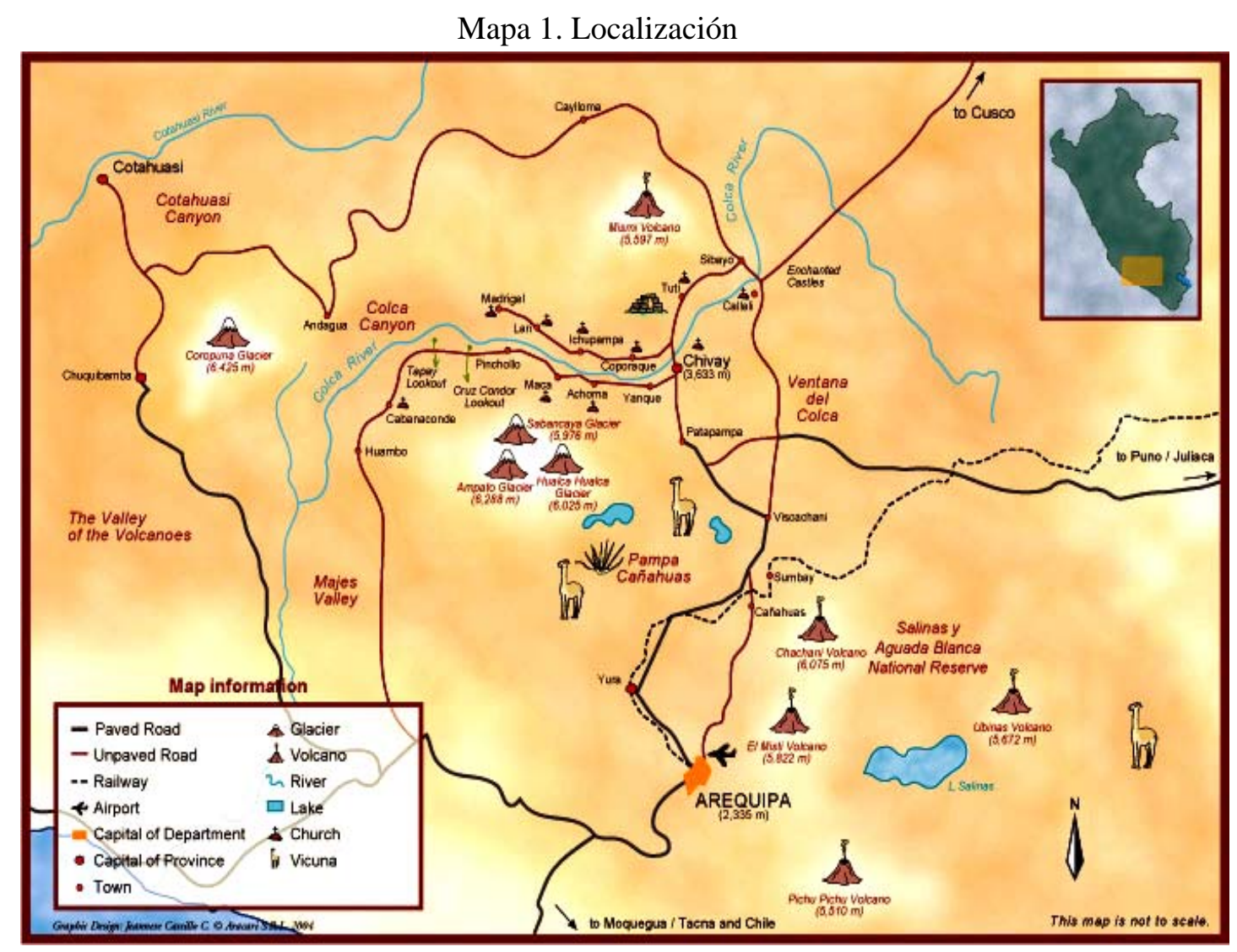

El 60\% de la población habitan en los distritos de Chivay, Cabanaconde y Yanque. El resto tienen una reducida población, entorno a mil habitantes (cuadro 1). El valle de Colca, cuenta con amplios áreas rurales nutridas de recursos naturales y culturales y con una población indígena que quieren ver revalorizadas sus culturas y tradiciones. El turismo comunitario ofrecer a los visitantes además de un contacto directo con la naturaleza la posibilidad de participar en tradiciones y estilos de vida de la comunidad local (MINCETUR, 2008b). 
CUADRO 1. Población del valle de Colca por distritos

\begin{tabular}{|c|c|c|}
\hline & \multirow[b]{2}{*}{2009} & \multirow[b]{2}{*}{2010} \\
\hline & & \\
\hline Chivay & 6.912 & 7.032 \\
\hline Achoma & 1.107 & 1.070 \\
\hline Cabanaconde & 2.798 & 2.727 \\
\hline Coporaque & 1.496 & 1.500 \\
\hline Ichupampa & 751 & 735 \\
\hline Lari & 1.502 & 1.506 \\
\hline Maca & 887 & 857 \\
\hline Madrigal & 666 & 634 \\
\hline Tapay & 655 & 635 \\
\hline Tuti & 875 & 854 \\
\hline Yanque & 2.327 & 2.294 \\
\hline Total & 19.976 & 19.844 \\
\hline
\end{tabular}

La población del valle de Colca presenta un elevado grado de pobreza. Se caracteriza por ostentar elevados niveles de pobreza y bajos ingresos asociados a una economía agraria (Baldárrago, 2007). Los indicadores socio-demográficos muestran que el 8,6\% de la población vive en situación de pobreza extrema, sin tener cubiertas sus necesidades básicas. Un elevado porcentaje de viviendas cuentan con las condiciones mínimas de vida saludable, luz, agua y alcantarillado. Además según el INEI (2010), la población presenta un elevado grado de analfabetización (6,3\%), el doble de Lima. Todo este repercute negativamente en la salud y en la calidad de vida de la población rural e indígena (cuadro 2).

El turismo comunitario puede ser una alternativa al fortalecimiento de la zona y puede contribuir a una reducción del nivel de pobreza, ya que una mayor participación de esta población en las actividades turísticas a través de pequeñas empresas familiares o comunales podría reducirla, de esa forma los beneficios generados se reinvertirían en la propia comunidad. Para la OMT (2003) la actividad turística que integra a las comunidades pobres, es en una de las actividades más eficaces para combatir la pobreza. Sin bien es necesario previamente mejorar las condiciones mínimas de las viviendas para que puedan ofertarlas a los turistas. 
Cuadro 2. Indicadores socio-demográficos del valle de Colca, 2010

\begin{tabular}{|c|c|}
\hline & 2010 \\
\hline Extensión (km2) & 11.990 \\
\hline $\begin{array}{l}\text { Población total } \\
\text { - \% varones } \\
\text { • } \% \text { mujeres } \\
\end{array}$ & $\begin{array}{r}19.884 \\
51 \% \\
49 \% \\
\end{array}$ \\
\hline $\begin{array}{l}\text { Pobreza } \\
\text { - } \quad \text { Pobreza total } \\
\text { - } \quad \text { Pobreza extrema } \\
\end{array}$ & $\begin{array}{r}36,6 \% \\
8,6 \% \\
\end{array}$ \\
\hline Mujeres que saben leer & $78 \%$ \\
\hline $\begin{array}{l}\text { Viviendas: } \\
\text { - } \quad \text { Con conexión de agua } \\
\text { - } \quad \text { Con luz eléctrica } \\
\text { - } \quad \text { Alcantarillado } \\
\end{array}$ & $\begin{array}{l}36 \% \\
34 \% \\
10 \%\end{array}$ \\
\hline
\end{tabular}

Fuente: Ministerio de Agricultura de Perú, 2010

En el valle del Colca viven dos etnias: Collaguas y Cabanas. Ambas se dedican a la agricultura y la ganadería, de ahí que el turismo puede ser una actividad complementaria pero no sustitutiva para la población indígena, ya que cuentan además del atractivo del valle y del cañón con un importante patrimonio cultural. La población indígena tiene sus raíces en la conciencia de permanencia a un grupo étnico, descendiente de pueblos originarios que ocuparon los territorios antes de la conquista. Su forma de organización, sus que se distinguen de la sociedad nacional.

El turismo comunitario tiene como objetivo la preservación de la identidad étnica, la valoración y transmisión del patrimonio cultural en todas sus formas. Las culturas autóctonas son portadoras de valores, de historia y de identidad (Maldonado, 2005). Además, puede aportar importantes beneficios en las áreas rurales, ya que tiene un impacto directo en las familias de la población local, en el desarrollo socioeconómico de la región y en el estilo de vida (Manyara y Jones, 2007. El éxito de este proceso, sólo será posible si la comunidad local la asume como propio, ya que lo que pretende en última instancia es llevar a la práctica una política que reconstituya un tejido local activo, en el que los proyectos se apoyen unos con otros de forma solidaria y donde puedan regularse los equilibrios sociales y económicos a nivel general, respetando a los individuos y colectividades, la armonía del empleo, y la vida cultural y social de cada comunidad local. ). Pero el impacto que tiene 
el turismo comunitario depende además del grado de implicación de la población indígena y del grado de acuerdo de las diferentes administraciones públicas y de la existencia de infraestructuras.

El valle de Colca cuenta con un sistema turístico desarrollado y con unas administraciones públicas que reflejan un decidido interés por el turismo. El Gobierno regional, la Gerencia Regional de Comercio Exterior y Turismo, es quien desarrolla las competencias en esta materia turística. Además, cuenta con un órgano propio para la gestión, la autoridad autónoma del valle del Colca (AUTOCOLCA), que es quien se encarga del desarrollo turístico del valle de Colca, concretamente de la promoción y de la conservación del patrimonio natural e histórico del valle.

Ya que el valle de Colca es, junto al Machu Picchu, uno de los destinos turísticos principales de Perú, cuenta con una buena información estadística elaborada tanto por el INEI y el MINCETUR como por Promperú, que dispone de una serie de estudio sobre el perfil del turista en diversos segmentos (aventura, negocios, cultural) como mercados de origen. Esto permite que las empresas turísticas conozcan el perfil de los turistas que lo visitan y se puedan adaptar a sus preferencias.

El sector privado está representado por la Asociación de Hoteles, Restaurantes y Afines de Arequipa (AHORA) que mantiene una muy completa página web con información sobre los atractivos, circuitos, recursos y oferta de la región y que cuenta con un apartado especial dedicado al valle del Colca.

Con respecto a las vía de acceso Arequipa cuenta con el aeropuerto Internacional Alfredo Rodríguez Ballón ubicado a unos 12 kilómetros del centro de la ciudad. Es el tercero en movimiento de pasajeros del país, tras Lima y Cuzco y fue utilizado en 2009 por más 500.000 pasajeros. Tiene conexiones nacionales con Lima, Cuzco y Juliaca. También tiene conexiones internacionales con Chile: Arica, Iquique, Santiago y Antofagasta.

Por carretera, la situación es desigual: de los aproximadamente $3.000 \mathrm{Km}$. de vías del departamento (sin contar las trochas), están asfaltados únicamente $890 \mathrm{Km}$. la carretera hasta Chivay, en el Valle del Colca, tiene tramos asfaltados y tramos sin asfaltar y en ocasiones se califica su mantenimiento como deficiente. La carretera hasta Cuzco es bastante buena y está bien conservada. Hay líneas de autobuses que conectan Arequipa con las principales ciudades del país, aunque los viajes por carretera suelen ser largos y poco confortables por el estado del firme (cuadro 3) 
Cuadro 3. Sistema de red vial región Arequipa

\begin{tabular}{|l|r||r||r|r|r||}
\cline { 2 - 6 } \multicolumn{1}{c|}{} & \multicolumn{1}{c|}{ Total } & Asfaltada & Afirmada & Sin Afirmar & \multicolumn{1}{l|}{ Trocha } \\
\hline \hline R. V. Nacional & $1.003,08$ & 619,03 & 241,50 & 72,10 & 70,45 \\
R. V. Departam. & $1.342,84$ & 192,76 & 475,40 & 400,58 & 274,10 \\
R.V. Vecinal & $3.740,80$ & 67,86 & 218,30 & 803,84 & $2.650,80$ \\
\hline \hline Total & $6.086,72$ & 879,65 & 935,20 & $1.276,52$ & $2.995,35$ \\
\hline
\end{tabular}

El turismo comunitario también es un medio eficaz para promover la igualdad de género dado que las actividades turísticas requieren una mayor participación del empleo femenino sobre el masculino (OMT, 2003). Las actividades turísticas pueden incrementar la independencia financiera de las mujeres y mejorar su capacitación (Baldarrago, E., 2007). Investigaciones han demostrado que la independencia financiera y una buena capacitación conduce a un mejoramiento de los niveles de vida y autoestima de las mujeres y unas relaciones más equitativas en las familias y las comunidades (OIT, 2002). Sin embargo, se debe tener en cuenta, que existen evidencias de que en algunas ocasiones la participación femenina en el turismo rural tiende a reforzar su papel tradicional, es decir, los empleos en los cuales se inserta son trabajos de la esfera doméstica similar al de ama de casa; reforzando este rol tradicional por lo que la participación como empresaria es mínima (Sparrer, 2003).

\section{4.- IMPORTANCIA DEL TURISMO EN DESARROLLO LOCAL DEL VALLE DEL COLCA.}

El turismo es un sector estratégico en la región de Arequipa, ya que representa una de las principales fuentes de exportaciones y de entrada de divisas, posibilita la diversificación de la economía local y puede orientarse hacia el desarrollo de áreas con pocas opciones de exportación, pero con una gran riqueza cultural.

La región de Arequipa es un importante destino turístico de Perú. Cuenta en 2010 con una población de 1.218.168 habitantes siendo la segunda población tras Lima y fue visitada durante 2010 por 146.818 turistas. Aunque no es posible cuantificar con exactitud la aportación del turismo al PIB de Arequipa, la proporción que supuso en 2010 el sector de Hoteles y Restaurantes fue del 2,3\% frente al 11,2\% del año anterior. 
Después de Lima y Cuzco es uno de los lugares más visitados actualmente por turistas extranjeros que llegaron a Perú (40\%) (MICETUR, 2010). Históricamente, es uno de los destinos con mayor atractivo para el turismo receptivo del Perú ya que sus principales recursos turísticos de la región son el Valle y Cañón de Colca y la propia ciudad de Arequipa, cuyo casco histórico fue declarado en 2000 Patrimonio Cultural de la Humanidad por la UNESCO.

El valle del Colca, de unos $100 \mathrm{Km}$. de largo, ocupa una parte de la cuenca del río Colca situada en el extremo nororiental de la región de Arequipa, en la provincia de Caylloma en Cabanaconde. Además del cañón del mismo nombre, una grieta espectacular formada por la erosión del río que alcanza en el punto máximo los 3.400 m. hay 11 pueblos escalonados a lo largo del valle, que conservan monumentos de la época colonial y restos arqueológicos. Además, del cañón y del valle se encuentra en la zona de la Reserva Nacional Salinas y Aguada Blanca, la Cruz del Cóndor, la laguna del Indio y el Bosque de piedras del Maurcarquipa.

Los recursos turísticos del valle del Colca se orientan fundamentalmente hacia el turismo de naturaleza, a través del disfrute del paisaje, ya que es uno de los paraísos más majestuosos de Perú, donde confluyen una impresionante geografía y un vasto legado histórico conservado por las culturas vivas que todavía habitan allí. En sus más de 100 kilómetros se esconden rincones de una belleza incomparable, y se han contabilizado hasta 115 puntos de interés naturales. También se orienta hacia la observación de la flora y fauna, ya que el cañón se ha convertido en el hábitat de innumerables especies y, en particular, del majestuoso cóndor andino. Allí se puede encontrar una fauna compuesta por más de 300 especies de plantas, más de 100 especies de aves y cuatro tipos de camélidos: la vicuña, el guanaco, la llama y la alpaca. Además, se puede practicar deportes de aventura, donde se puede practicar deportes como la bicicleta de montaña, el canotaje o el trekking.

El valle de Colca también se orienta al turismo cultural, donde hay importantes restos arqueológicos de los incas, sobre todo en Chivay; y obras arquitectónicas, principalmente templos religiosos, distribuidas por todo el valle que mezclan diferentes estilos arquitectónicos: renacentista, barroco y neoclásico.

Además hay una cultura viva, las etnias de los Collaguas y los Cabanas que han preservado su rico folclore, que se suelen representar en las fiestas costumbristas, como el Wititi, el Qamili, el Tincachi, los Carnavales, el Turcu Tusuy y las Corridas de Toros; una importante artesanía, a base de 
fibra de alpaca y llama elaborados por los pueblos de la parte alta del valle. Los poblados del valle han atravesado épocas difíciles pero actualmente brillan por sus bordados, telares y talleres artesanales, gracias a un interesante proyecto de turismo comunitario implantado en la zona. Especialmente, cabe destacar la vistosidad de sus trajes típicos, la lengua quechua, así como ritos ancestrales y antiguas leyendas. Inicialmente sus antecesores fueron grandes trabajadores agrícolas y artífices de canales de riego y extensas áreas de andenerías. La riqueza en expresiones culturales milenarias es una de las grandes señas de identidad de Perú. De ahí que uno de los grandes atractivos es el verdadero intercambio cultural con las comunidades locales. En definitiva, una ruptura con la actividad que desarrollan los circuitos turísticos convencionales y un enriquecimiento de primera mano para el que lo experimenta.

El patrimonio cultural y el patrimonio natural son indisociables, interdependientes y complementarios. La gestión sostenible del patrimonio cultural y natural exige convergencias en los instrumentos legales y en las medidas promocionales para preservar el patrimonio. Los pueblos indígenas mantienen importantes vínculos con la naturaleza y la respetan profundamente (Maldonado, 2005).

Incluso hay también una importante modalidad turística, el turismo de salud, ya que hay aguas termales, desde Caylloma hasta Canco, y de géiseres en Pinchollo, Cabanaconde y Tapay, lo que indica la presencia de focos volcánicos que provocan las elevadas temperaturas del agua subterránea cuando aflora a la superficie.

El producto turístico se basa en el aprovechamiento del recurso esencial, el valle y el cañón del Colca que es, en lo esencial un producto de naturaleza, aunque la propia singularidad y espectacularidad de los paisajes y miradores del cañón le confieren rasgos de producto vivencial. Sobre este recurso básico se han ido organizando los distintos productos, que ofrecen distintas posibilidades de disfrute y pretenden alcanzar diversos mercados. Así encontramos desde productos de aventura (recorridos del valle en trekking, en bicicleta, a caballo), productos que incluyen un componente cultural (sea arqueológico o etnográfico), la combinación con otros recursos (aguas termales) o bien la combinación con los atractivos monumentales de la propia ciudad de Arequipa y su entorno.

El valle del Colca es un destino internacional como se aprecia en el cuadro 4. La cifra de visitantes extranjeros es de un 67,7\% frente al 32,3\% de nacionales. Los turistas extranjeros 
provienen principalmente de Europa (cinco países de la Unión Europea suponen el 47 \% del total) y de EE.UU. El cuadro 5 muestra la composición por países de los visitantes extranjeros llegados a Arequipa.

Cuadro 4.- Evolución de los visitantes al valle del Colca, 2006 - 2010

\begin{tabular}{|c|c|c|c|c|c|}
\hline & 2006 & 2007 & 2008 & 2009 & 2010 \\
\hline \multicolumn{6}{|c|}{ Visitantes al cañón del Colca } \\
\hline Total viajeros & 118.686 & 122.636 & 140.613 & 146.818 & 169.582 \\
\hline Nacionales & 26.683 & 31.288 & 38.458 & 48.082 & 59.960 \\
\hline Extranjeros & 92.003 & 91.348 & 102.155 & 98.736 & 100.622 \\
\hline
\end{tabular}

Fuente: Base de Datos turística (BADATUR). INEI y MINCETUR

Cuadro 5.- Proporción por nacionalidades de visitantes extranjeros llegados a Arequipa, 2010

\begin{tabular}{|l|r|}
\cline { 2 - 2 } \multicolumn{1}{c|}{} & Porcentaje \\
\hline Francia & $16,9 \%$ \\
\hline \hline Reino Unido & $9,0 \%$ \\
\hline \hline Alemania & $8,1 \%$ \\
\hline \hline España & $8,0 \%$ \\
\hline \hline Estados Unidos & $9,3 \%$ \\
\hline Italia & $5,0 \%$ \\
\hline Otros & $43,1 \%$ \\
\hline Total & $100 \%$ \\
\hline Fuente: Base de Datos turística (BADATUR). INEI y MINCETUR
\end{tabular}

Se espera que continúe creciendo en los próximos años la llegada de turistas, debido al aumento del turismo mundial y a la mejora de las condiciones socio-políticas del país, que en el actual momento lo hacen un sitio vacacional más seguro que en años anteriores. Este flujo creciente de turistas de países desarrollados hacia los países en vías de desarrollo, constituyen una importante demanda potencial para las empresas locales ubicadas en las zonas turísticas.

En cuanto a la oferta turística, el valle de Colca cuenta con hoteles de 3 estrellas, aunque hay que destacar que el $44 \%$ de los establecimientos de alojamientos estén sin catalogar y el 17\% sean casas de hospedaje (cuadro 6). Además, veremos que debido al Proyecto de Turismo Comunitario, 
que analizaremos en el apartado siguiente, han aparecido en el distrito de Sibayo un modelo de establecimiento en que las viviendas de la población local, denominadas "casa vivencial”, se ofrecen a los turistas para hacer un tipo de turismo distinto en el que el turista participa en la vida de la población indígena de la zona.

Con respecto al promedio de permanencia es de 1,3 días elevándose a 1,5 los turistas extranjeros (BADATUR, 2010). Sin embargo, el nivel de ocupación es bajo, ya que el porcentaje de habitaciones y camas ocupadas al mes es de un 23\% (BADATUR, 2010) (cuadro 6).

Un problema de la actividad turística de esta zona es la elevada estacionalidad. El perfil estacional de los flujos turísticos es característico de este tipo de destinos y tiene una elevada similitud con el de Cuzco-Machu Picchu por razones idénticas: un pico estacional importante en los meses de julio y agosto, ya que los mercados principales son Europa y EE.UU. y un segundo máximo en los meses de octubre y noviembre (sobre todo este último) que se corresponde con las vacaciones de los habitantes de la región suramericana. En temporada baja la oferta turística queda subutilizada ya que no logra atraer con eficacia a la oferta nacional y latinoamericana de nivel medio que resultaría estratégica para cubrir esta temporada. Esta situación crea problemas en la oferta que no tiene constantes los niveles de ocupabilidad, mientras que en los meses de exceso de demanda crea problemas de cogestión y sobreabastecimiento de servicios.

Cuadro 6.- Establecimientos de alojamiento en el valle del Colca, 2009

\begin{tabular}{|l|c||c|c|}
\cline { 2 - 4 } \multicolumn{1}{c|}{} & Establecimientos & Habitaciones & Plazas \\
\hline 3 estrellas & 4 & 126 & 252 \\
\hline 2 estrellas & 3 & 99 & 202 \\
\hline \hline Hostales & 7 & 99 & 218 \\
\hline Albergues & 4 & 114 & 293 \\
\hline Casas de hospedaje & 22 & 221 & 406 \\
\hline $\begin{array}{l}\text { Total establecimientos registrados } \\
\text { por MINCETUR }\end{array}$ & 40 & 659 & 1.371 \\
\hline No registrados & 54 & 454 & 1.075 \\
\hline Total & 94 & 1.113 & 2.446 \\
\hline \hline
\end{tabular}




\section{5.- ANÁLISIS PROYECTO PILOTO DE TURISMO RURAL COMUNITARIO EN SIBAYO EN EL VALLE DE COLCA.}

Dentro del Programa de Cooperación Hispano Peruano 2007-2010 se aprobó un proyecto, por parte de la Agencia Española de Cooperación Internacional al Desarrollo (AEID), el Ministerio de Comercio Exterior y Turismo de Perú (MINESTUR) y el Gobierno Regional de Arequipa, denominado "Desarrollo y Fortalecimiento del Turismo Rural Comunitario en Perú, TURURAL PERÚ”, dirigido a “fortalecer el desarrollo del Turismo Rural Comunitario en el Perú como instrumento de lucha contra la pobreza, a través de una política nacional promotora de la participación de las comunidades rurales, la formación de recursos humanos y la acción promotora de los gobiernos regionales y/o locales” (MINCETUR-AECID, 2007).

Los ejes de este proyecto son el fortalecer a la institución pública mediante una política nacional promotora del Turismo Rural Comunitario, capacitar los recursos humanos en turismo rural y detectar nuevos recursos turísticos para convertirlos en herramientas del desarrollo comunitario.

El ámbito de aplicación se ha dirigido:

- En la región de Puno, al distrito de Capachica en el Lago Titicaca

- En la región de Arequipa, al distrito de Sibayo en el valle de Colca

- En la región de Lima, a la provincia de Canta

- En la región de Loreto, al poblado del lago Cuipari

- En la región de Apurimac, al distrito de Huanipaca

En este proyecto hay un enfoque de género, ya que tiene que haber una participación equitativa de hombres y mujeres fomentando su formación en áreas básicas de turismo como su inserción laboral.

Centrándonos en el distrito de Sibayo en el valle de Colca, lo que se ha conseguido ha sido mejorar la formación de los funcionarios de la Autoridad Autónoma del Valle de Colca (AUTOCOLCA), se ha consolidado el Programa de Concientización Turística y se ha ejecutado un proyecto de turismo rural comunitario en el cual 11 viviendas se han remodelado y acondicionado para recibir a turistas nacionales y extranjeros como "casa vivencial”, quienes comparten con los lugareños sus actividades cotidianas. Los turistas demandan este tipo de turismo vivencial, ya que les permite compartir costumbres, festividades y otras actividades con los lugareños. De todos los turistas 
que vienen al valle, los que demandan esta modalidad turística con los procedentes de Francia, Alemania e Italia. Si bien este proyecto es muy incipiente, según el Ministerio de Comercio Exterior y Turismo de Perú, estas familias han visto incrementar sus ingresos diarios un 30\%. Una vez iniciado en Sibayo, se ha empezado a extender a Cabanaconde, Coporaque y Lari.

\section{6.- CONCLUSIONES}

El objetivo del Turismo Comunitario tal y como se desprende del trabajo es esencialmente mejorar el nivel de vida de los habitantes de las comunidades nativas, mediante la utilización de los recursos turísticos. Con esto se consigue reanimar las zonas deprimidas, aumentar y garantizar la permanencia de formas de vida tradicionales, crear una actividad económica complementaria a las formas productivas tradicionales; en el caso de la región de Arequipa a la agricultura, que fortalezca dichas prácticas para incrementar su consumo por parte de los turistas, contribuir a la generación de empleo y la reanimación a través del turismo; especialmente del colectivo más desfavorecido en los países en vías de desarrollo las mujeres, propiciar la integración entre los municipios urbanos y rurales incrementando los contactos a través del turismo que permitan una mejor coordinación y repartición equitativa de sus beneficios, contribuir a la descentralización de las instituciones y promover la cooperación intermunicipal, propiciar el intercambio sociocultural y facilitar procesos de comprensión entre las comunidades nativas integrantes, poner en valor el patrimonio natural y cultural disponible en las comunidades nativas y, al mismo tiempo, crear conciencia y respeto al ambiente cultural y comunitario.

Por todo ello el Turismo Comunitario implica no solo un componente económico y de lucha para erradicar la pobreza; incide además en otras actividades esenciales como son la revalorización de la cultura inca de las comunidades nativas, la recuperación de los productos nativos y la protección de los recursos naturales.

Después del análisis se constata que los desafíos del valle del Colca en términos de desarrollo sostenible y la distribución equitativa de los ingresos generados por la industria turística apuntan hacia la consolidación de un nuevo modelo de gestión del turismo en la región y el más conveniente es el modelo del Turismo Comunitario por las características socio-económicas de la región y por el tipo de modelo de gestión de desarrollo turístico que se viene desarrollando en Perú que tiene como principal eje de atracción el Santuario Histórico de Machu-Picchu operado principalmente por tour 
operadores internacionales. Esta situación genera una dificultad para conciliar los intereses de desarrollo económico local y los intereses internacionales. Además la región tiene un gran potencial para desarrollar este modelo por los atractivos de la cultura inca, pero la actividad turística de la región adolece de grandes carencias de infraestructuras y es necesario regularizar el sector turístico y acometer más proyectos y políticas turísticas en esta dirección.

\section{BIBLIOGRAFIA}

BALDÁRRAGO, E. (2007): Turismo y desarrollo económico local: El caso del Cañón del Colca en la Provincia de Caylloma-Arequipa, Consorcio de Investigación Económica y Social y Universidad Nacional de San Agustín de Arequipa, Arequipa.

BOLWEL D. Y WEINZ, W. (2009): Reducir la pobreza a través del turismo, Documento de trabajo, Organización Internacional del Trabajo, Ginebra. ISBN: 978-92-2-321644-3.

GUERREIRO MARCÓN, E. M. (2007): “O Turismo comunitario como agente de desenvolvimento social e a comunidade Guarani nas Ruinas Jesuíticas de São Miguel das Missões” Revista de Turismo y Patrimônio Cultural, vol. 5, págs. 343-352, ISNN: 1695-7121

INEI (2010): Principales Indicadores Departamentales 2006-2009, INE, Lima.

INOSTROZA, G. (2009): “Aportes para un modelo de gestión sostenible del turismo comunitario en la región andina”, Gestión Turística, nº 10, ISSN: 0717-1811

JUÁREZ SÁNCHEZ, J. P. Y RAMÍREZ VALVERDE, P. (2008): “Turismo rural como complemento al desarrollo territorial rural en zonas indígenas de México" Scripta Nova. Revista Electrónica de Geografía y Ciencias Sociales. Universidad de Barcelona, ISNN: 1138-9788.

KAY, C. Y BRETON, V. (2007). La cuestión agraria y los límites del neoliberalismo en América Latina. Iconos. Revista de Ciencias Sociales. No 28, Quito, pp. 119-133. Facultad Latinoamericana de Ciencias Sociales-Sede Académica de Ecuador.

LÓPEZ GÚZMAN T. Y SÁNCHEZ CAÑIZARES, S. M. (2009): “Turismo Comunitario y Generación de Riqueza en países en vías de desarrollo. Un estudio de Caso en el Salvador”, REVESCO, nº 99, pág. 85-103. ISNN: 1885-8031

LÓPEZ GUZMÁN T. Y SÁNCHEZ CAÑIZARES, S. M. (2009a): "Desarrollo socioeconómico de las zonas rurales con base en el turismo comunitario. Un estudio de caso de Nicaragua”, Cuadernos de Desarrollo Rural, nº 6, págs. 81-97. ISNN: 0122-1450. 
MALDONADO C. (2005): Pautas metodológicas para el análisis de experiencias de turismo comunitario, Documento de trabajo $\mathrm{n}^{\circ} 13$ de la Oficina Internacional de Trabajo, Ginebra, ISBN: 92-2-317378-7.

MANYARA, G. Y JONES, E. (2005): "Policy options for the development of an indigenous tourism SME sector in Kenya”, Tourism SMEs, Service Quality and Destination Competitiveness, CABI publishing, London, págs. 628-64.

MANYARA, G. Y JONES, E. (2007): “Community-based tourism enterprises development in Kenya: An exploration of their potential as avenues of poverty reduction”, Journal of Sustainable Tourism, Vol. 15, págs. 628-644. ISNN: 1747-7646.

MINCETUR-AECID (2007): Desarrollo y Fortalecimiento del Turismo Rural Comunitario en el Perú, TURURAL, PERÚ, Ministerio de Comercio Exterior y Turismo, Perú.

MINCETUR (2008): Plan estratégico Nacional de Turismo, PENTUR (2008-2018), Ministerio de Comercio Exterior y Turismo, Perú.

MINCETUR (2008a): Plan Estratégico Institucional de Arequipa (2008-2010), Ministerio de Comercio Exterior y Turismo, Perú.

MINCETUR (2008b): Lineamientos para el Turismo Rural Comunitario en el Perú, Ministerio de Comercio Exterior y Turismo, Perú.

MINCETUR (2010): Plan Estratégico Regional de Turismo en Arequipa (2011-2015), Ministerio de Comercio Exterior y Turismo, Perú.

MORALES MORGADO, H.F. (2006): "Turismo Comunitario: una alternativa de desarrollo indígena”. AIBR. Revista de Antropología Iberoamericana. Ed. Electrónica. Vol. 1. Núm. 2. Págs. 249-264. ISSN. 1578 - 9705.

MURPHY, P.E. (1985): Tourism: A community approach. Londres. Methuesen, págs. 200. ISBN: 0461-359030-2

MURPHY, P.E, Y MURPHY, A.E. (2004): Strategic management for tourism communities: Bridging the gaps. Clevedon: Channel Wiew Publications, págs. 448. ISBN: 1873150830.

OIT (2002): Gestión del turismo sostenible y competitivo. Alianzas entre Estado, empresa y comunidad. Los casos de Bolivia, Ecuador y Perú. OIT/Equipo Técnico Multidisciplinario para los Países Andinos, Lima.

OMT (2002): Manual on Tourism and poverty alleviation,. Madrid; OMT, Madrid. ISBN: 978-92844-1343-0

OMT (2003): Tourism and poverty alleviation, OMT, Madrid. ISBN: 978-92-844-0549-7

PALMA, L (2010): El valle de Colca y la Ruta de Lonco: territorios con riqueza natural y cultural. Proyecto de Desarrollo Sierra Sur, Ministerio de Agricultura, Perú.

PROMPERU (2007): Perfil del turista extranjero, 2007. Promperú.

RICHARDS, G. Y HALL, D. Tourism and sustainable community development, Londres. Routledge. ISBN: 0415224624. 
RUIZ, E. ET AL (2008): “Turismo comunitario en Ecuador. Comprendiendo el community-based tourism desde la comunidad”, Revista de Turismo y Patrimonio Cultural, vol. 6, págs. 399-418, ISNN: 1695-7121.

SPARRER, MARION (2003), Género y turismo rural. El ejemplo de la costa coruñesa. Cuadernos de Turismo, Número 11, pp.181 - 197.

WWF INTERNACIONAL (2001): Directrices para el desarrollo de turismo comunitario, WWF Internacional, Suiza.

Recibido: 24/05/2011

Aprobado: 15/06/2011

Arbitrado anónimamente 